\title{
Cellular immune responses to $\beta$ casein: elevated in but not specific for individuals with Type I diabetes mellitus
}

\author{
T. M. Ellis ${ }^{1}$, E. Ottendorfer ${ }^{1}$, E. Jodoin ${ }^{1}$, P.J.Salisbury ${ }^{2}$, J. X.She ${ }^{1}$, D. A.Schatz ${ }^{2}$, M. A. Atkinson ${ }^{1}$ \\ ${ }^{1}$ Department of Pathology, University of Florida College of Medicine, Gainesville, Florida, USA \\ ${ }^{2}$ Department of Pediatrics, University of Florida College of Medicine, Gainesville, Florida, USA
}

\begin{abstract}
Summary Elevated cellular immune responses against the cows' milk protein $\beta$ casein have been reported in individuals with Type I diabetes mellitus, a finding supportive of the concept that cows' milk consumption may be causative for the disease. We analysed cellular immune reactivities against $\beta$ casein in newly-diagnosed Type I diabetic patients, their immediate autoantibody negative relatives, and unrelated healthy individuals in order to further elucidate the role of anti- $\beta$ casein immunity in the pathogenesis of Type I diabetes mellitus. Peripheral blood mononuclear cells were stimulated in vitro with various concentrations of three different $\beta$ casein preparations, control antigens (tetanus toxoid, mumps extract) and a mitogen (phytohemagglutinin). The frequency and/or mean simulation index of cellular proliferation against two of the $\beta$ casein preparations at high antigen concentrations (i.e. 10 or $50 \mu \mathrm{g} / \mathrm{ml}$ ) were significantly higher in newly-diagnosed Type I diabetic subjects compared with autoantibody nega-
\end{abstract}

tive healthy control subjects. However, reactivities against $\beta$ casein in the Type I diabetic probands and their autoantibody negative relatives, individuals with a very low-rate of disease development, were almost identical. Cellular immune reactivities to other antigens were similar between the subject groups. In addition to indicating the need for appropriately matched subject populations (e.g. human leukocyte antigen (HLA) matched relatives) when analysing cellular immune responses, these findings support our previous contention that individuals genetically prone to autoimmunity may be deficient in forming tolerance to dietary antigens. However, the significance of anti- $\beta$ casein immunity as a specific causative factor in the pathogenesis of Type I diabetes mellitus remains unclear.

Keywords T-lymphocytes, insulin dependent diabetes mellitus, autoantibodies, autoimmunity, diet [Diabetologia (1998) 41: 731-735
Type I diabetes mellitus appears as the end result of an autoimmune destruction of the insulin secreting pancreatic beta cells [1]. The immunological mechan-

Received: 22 December 1997 and in revised form: 9 March 1998

Corresponding author: Dr. M. A. Atkinson, Department of Pathology, Box 100275, University of Florida College of Medicine, Gainesville, FL 32610, USA.

Abbreviations: BSA, Bovine serum albumin; NOD, non obese diabetic; PBMC, peripheral blood mononuclear cells; GAD, glutamic acid decarboxylase; ICA, islet cell cytoplasmic autoantibodies; IAA, insulin autoantibodies; PHA, phytohaemaglutinin; SI, stimulation index; HLA, human leukocyte antigen. isms underlying the development of Type I diabetes mellitus as well as the role of environmental agents (e.g. diet, viruses, stress) in the pathogenesis of the disease have been the subject of considerable research. The rationale for investigating environmental agents involves an attempt to explain numerous epidemiological observations including the disease discordance rate amongst twins with Type I diabetes mellitus, a pronounced north-south gradient in the incidence of Type I diabetes mellitus, reports of an increased (e.g. up to fourfold) incidence of Type I diabetes mellitus over the past three decades, and the estimate that more than $80 \%$ of patients with newly-diagnosed Type I diabetes mellitus do not have a firstdegree relative with the disease [2]. 
Significant attention has been directed recently at the hypothesis that consumption of cows' milk in infancy may trigger the autoimmune process underlying Type I diabetes mellitus [3-5]. Early evidence supporting this "cows' milk hypothesis" included case-control studies surveying infant nutritional practices (i.e. breast-feeding vs consumption of infant formula) and the subsequent development of Type I diabetes mellitus. Additional evidence included reports that the frequency of disease in animal models for human Type I diabetes mellitus, the BB rat and non-obese diabetic (NOD) mouse, can be modified (i.e. enhanced or prevented) through the alteration of cows' milk components within dietary chows. Furthermore, reports exist indicating enhanced humoral or cellular immunity or both in Type I diabetic patients to various components of cows' milk including $\beta$-lactoglobulin [6] and (most notably) bovine serum albumin (BSA) [7]. These three lines of evidence have been molded into a hypothesis which portends that the autoimmune nature of Type I diabetes mellitus is triggered by consumption of cows' milk based infant formulas too early in the life of persons genetically predisposed to Type I diabetes mellitus.

Recently, this hypothesis was bolstered by the observation that individuals with Type I diabetes mellitus displayed elevated cellular immune reactivities to an additional cows' milk component, $\beta$ casein [8]. Specifically, elevated cellular immunity to $\beta$ casein was observed in most newly-diagnosed Type I diabetic subjects, $2 \%$ of healthy control subjects but not in persons with autoimmune thyroid disease. This finding complemented previous works indicating that casein could modify the frequency of disease in NOD mice and the identification of anti-casein antibodies in persons with Type I diabetes mellitus [9]. The latest report [8], while encouraging in relating $\beta$ casein to the mechanism most often associated with beta cell destruction (i.e. cellular immunity), failed to report investigations involving analysis of subjects more similar in their genetic risks for the disease. Additional unanswered questions involved issues regarding dose-dependency and the source(s) of antigen for the detection of such responses. These issues form the subject of this investigation.

\section{Subjects and methods}

Patients. Blood samples were obtained from 71 individuals involved in our ongoing studies of the natural history of Type I diabetes mellitus [10] including 32 newly-diagnosed patients (aged $13 \pm 9.9$ (SD) years; 15 male/17 female). Samples were collected from patients within only 3 days of the onset of initial insulin therapy. In addition, samples were obtained from 29 islet cell cytoplasmic (ICA) and insulin autoantibody (IAA) autoantibody negative first-degree relatives (aged $25 \pm$ 13.6 years; 11 male/18 female) of the Type I diabetic subjects used in this study. Ten autoantibody negative healthy volun- teers (aged $23 \pm 8.9$ years; 7 male $/ 3$ female) with no family history of Type I diabetes mellitus participated to establish normal control ranges for cellular immune responses. Informed consent was obtained from each subject or their parents or both as approved by the University of Florida Institutional Review Board. HLA typings were performed as described previously [10]. The respective distribution of specific HLA-DR combinations in subjects available or submitting to genetic testing were as follows: newly-diagnosed IDDM subjects ( $n=25,5 \mathrm{DR} 3 / 4,7 \mathrm{DR} 4 / \mathrm{X}, 12 \mathrm{DR} 3 / \mathrm{X}$, and $1 \mathrm{DR} \mathrm{X} / \mathrm{X})$; autoantibody negative first-degree relatives of the Type I diabetic subjects $(n=23,2 \mathrm{DR} 3 / 4,9 \mathrm{DR} 4 / \mathrm{X}, 6 \mathrm{DR} 3 / \mathrm{X}$, and $6 \mathrm{DR} \mathrm{X} /$ $\mathrm{X})$; and healthy control subjects $(n=8,1 \mathrm{DR} 3 / 4,2 \mathrm{DR} 4 / \mathrm{X}$, 1 DR $3 / X$, and 4 DR $\mathrm{X} / \mathrm{X}$ ).

Autoantibodies. ICA were determined by indirect immunofluorescence using unfixed, snap frozen human pancreata [10]. IAA were determined and reference ranges for positivity established as described previously [10]. Our laboratory is a regular participant in international autoantibody workshops designed for assay standardization and proficiency.

Antigens. The highest grade of $\beta$ casein available commercially was purchased from three manufactures: ICN (no.100231; $\geq 90 \%$ purity; Costa Mesa, Calif., USA), Fluka Chemical (no.22086; $\geq 80 \%$ purity; Ronkonkoma, N.Y., USA), and Sigma Chemical (no.C6905; $\geq 90 \%$ purity; St.Louis, M.O. USA). Other stimulatory reagents were also purchased from commercial sources: Tetanus toxoid (Massachusetts Public Health Biological Laboratories, Boston, Mass., USA); Mumps extract (Merck, Sharp, and Dohme, Westpoint, Pa, USA); and PHA (Sigma Chemical).

Lymphocyte stimulation assay. Peripheral blood mononuclear cells (PBMC) were isolated and seven day lymphocyte stimulation's performed as described previously [10]. The cells were incubated with the following antigen/mitogens in triplicate cultures: 1,10 and $50 \mu \mathrm{g} / \mathrm{ml}$ of each $\beta$ casein; $10 \mu \mathrm{g} / \mathrm{ml}$ (0.875 Lyons floculating units $/ \mathrm{ml}$ ) Tetanus toxoid; 80 tissue culture infectious doses (TCID) $)_{50} / \mathrm{ml}$ ) Mumps extract; and $10 \mu \mathrm{g} / \mathrm{ml}$ phytohaemaglutinin (PHA). We added $1 \mu \mathrm{Ci}^{3} \mathrm{H}$ thymidine to each well $19 \mathrm{~h}$ prior to harvest. The mean value of each triplicate stimulation was determined, with cellular proliferation expressed as a stimulation index (SI): mean counts per minute $(\mathrm{cpm})$ incorporated in the presence of antigen divided by the mean cpm incorporated in antigen absence (medium alone). A positive cellular immune response was defined as an SI of greater than mean plus 2 SD of the healthy control responses for test antigens. PHA responses were measured after 4 days. Analysis of differences between study groups was performed using both analysis of variance (ANOVA) and Fisher's exact testing. Values of $p$ less than 0.05 were deemed as representing significance.

\section{Results}

PBMC proliferation in response to recall antigens and mitogen were evaluated in short-term in vitro cultures established from the newly-diagnosed Type I diabetic patients, autoantibody negative relatives and healthy control subjects. No significant differences were observed between these subject groups in their levels of proliferation to the recall antigens. Specifically, the mean (SD) SI in newly-diagnosed 

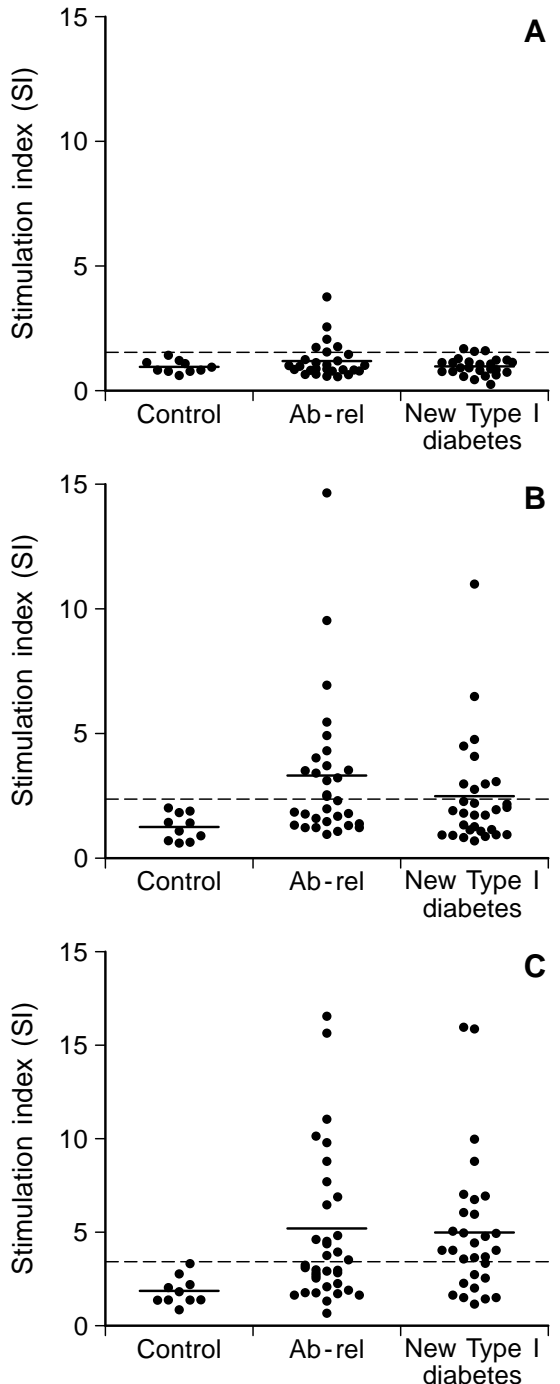

Fig.1A, B, C. Proliferation of peripheral blood mononuclear cells in response to Fluka $\beta$ casein. Aliquots of PBMC $\left(1 \times 10^{5}\right)$ were cultures of medium containing (A) $1 \mu \mathrm{g} / \mathrm{ml}$, (B) $10 \mu \mathrm{g} / \mathrm{ml}$, or (C) $50 \mu \mathrm{g} / \mathrm{ml} \beta$ casein. Dashed lines represent thresholds for positive reactivity. Solid bars indicate the group mean. Ab-rel, autoantibody negative relatives

Type I diabetic patients, autoantibody-negative relatives and healthy control subjects (respectively) were: tetanus (24.5 [24.7]; 14.9 [11.8]; 18.6 [15.7], $p=$ not significant); mumps (2.3 [1.8]; 2.9 [2.6]; 5.1 [9.9], $p=$ not significant). Mitogenic responses were high in all study groups (newly-diagnosed Type I diabetic patients, 243 [184]; autoantibody negative relatives, 306 [214]; healthy control subjects, 377 [166]), with no significant differences observed in their levels of mitogenic stimulation ( $p=$ not significant).

As shown in Figures 1,2, and 3, elevated cellular immune responses to $\beta$ casein were often observed in newly-diagnosed Type I diabetic patients and their autoantibody negative relatives in comparison with healthy control subjects. In terms of the frequency of such responses as a function of manufacturer and an-
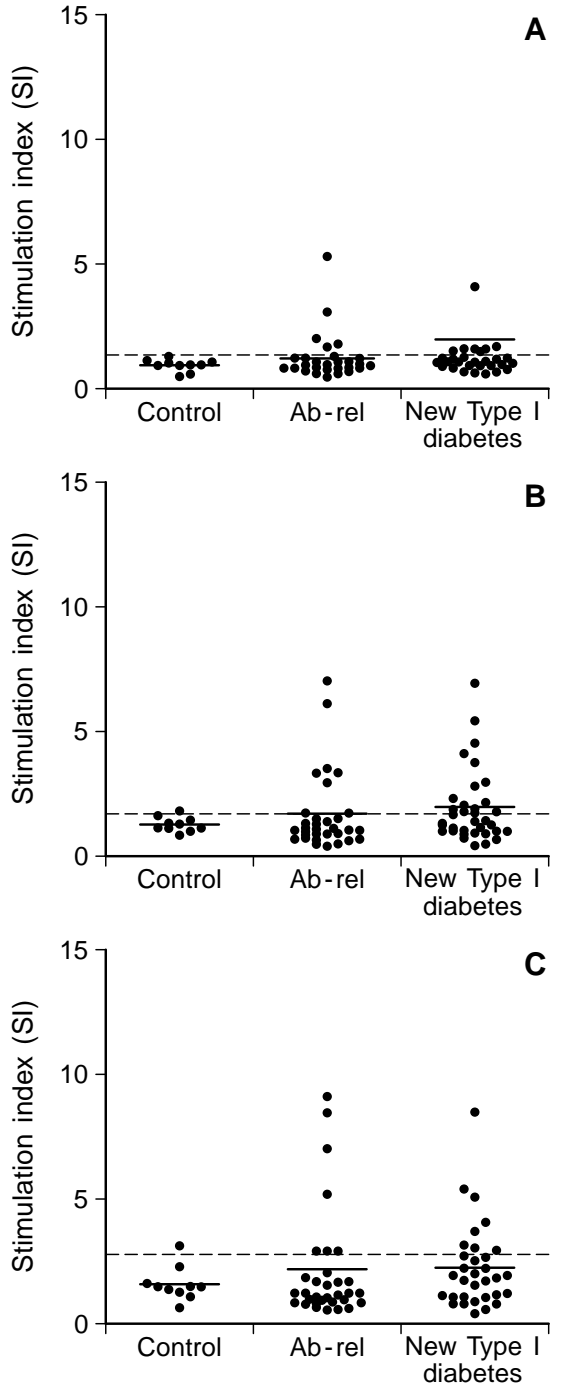

Fig. 2A-C. Proliferation of peripheral blood mononuclear cells in response to ICN $\beta$ casein. Dashed lines represent thresholds for positive reactivity. Solid bars indicate the group mean. Ab-rel, autoantibody negative relatives

tigen concentration, these rates varied from zero to $10 \%$ in healthy control subjects, 17 to $52 \%$ in autoantibody negative relatives, and 9 to $62 \%$ in newlydiagnosed Type I diabetic subjects (Table 1). Statistical comparison of these frequencies showed significant differences between both newly-diagnosed and autoantibody negative relatives compared with healthy control subjects at $10 \mu \mathrm{g} / \mathrm{ml}$ concentrations in the $\beta$ casein preparations from two of the three product manufacturers (Table 1). At the highest antigenic concentration, only one preparation of $\beta$ casein showed significant differences in the frequency of response between the subject groups (Table 1). Comparison of the mean SI against $\beta$ casein in all three study groups (Table 1) also showed higher levels of anti- $\beta$ casein immunity in newly-diagnosed subjects and autoantibody negative relatives compared with healthy control subjects which were both dose- and 

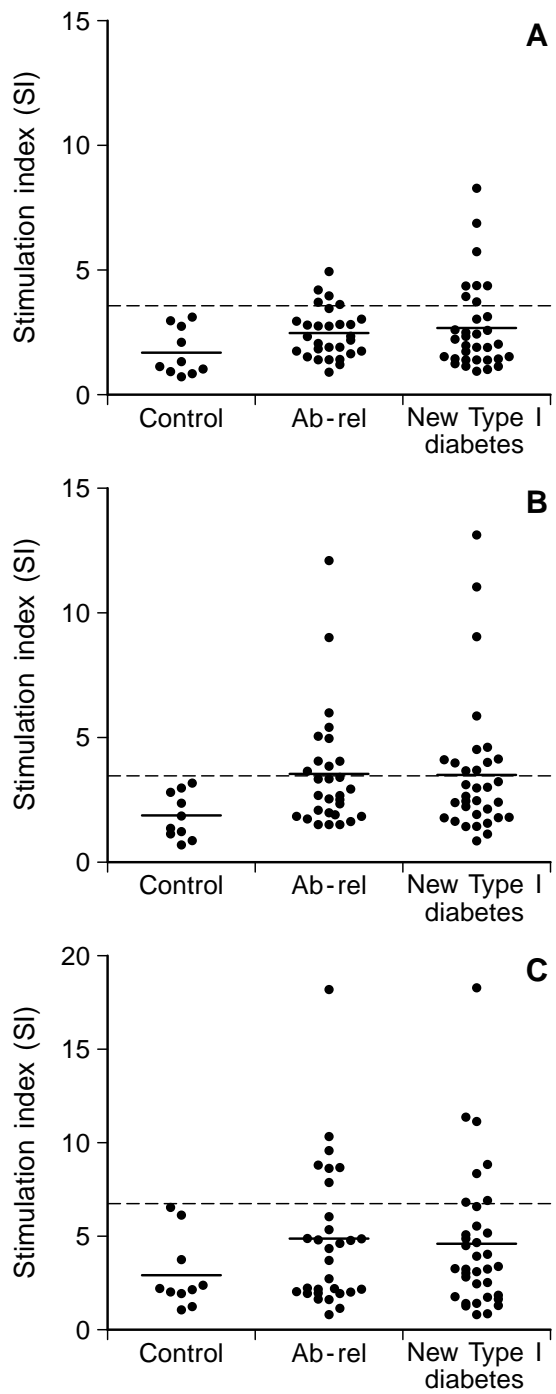

Fig.3 A-C. Proliferation of peripheral blood mononuclear cells in response to Sigma $\beta$ casein. Dashed lines represent thresholds for positive reactivity. Solid bars indicate the group mean. Ab-rel, autoantibody negative relatives

manufacturer-dependent. However, no statistical differences were observed in the frequency or level of stimulation (Table 1 ) against $\beta$ casein in newly-diagnosed subjects and autoantibody negative relatives with products from either of the manufacturers at any concentration. Statistical examination of parameters that could potentially influence anti- $\beta$ casein immunity (sex, age, HLA-type) in responding/non-responding groups failed to identify an association for such variables. Furthermore, the frequency of $\beta$ casein responses in autoantibody positive and autoantibody negative newly-diagnosed subjects were similar (75 and $83 \%, p=0.9$ ).

\section{Discussion}

Our studies confirm previous observations [8] that a significantly greater proportion of Type I diabetic patients display a PBMC response against $\beta$ casein compared with healthy persons with no family history of the disease. However, most noteworthy is our finding that non-diabetic individuals genetically more similar to Type I diabetic patients than healthy control subjects also demonstrate elevations in immune reactivity to $\beta$ casein. Potential explanations (among many) are that these studies involved investigation of autoantibody negative relatives who were in reality seronegative prediabetics, or that the HLA types controlling $\beta$-casein reactivity were markedly dissimilar between the two groups. In reality, the distribution of HLA-types was similar between the newly-diagnosed and autoantibody negative relatives and no specific HLA-DR type was associated with cases of anti- $\beta$ casein immunity. Hence, the mechanisms underlying the lack of association with HLA and the relationship of Type I diabetic probands with anti- $\beta$ casein response remains subject to further investigation.

Our investigations also indicate that this immune response expresses itself in a dose-dependent fashion and that the commercial source of antigen can influence the results observed in these in vitro reactions. In the aforementioned study [8] Sigma $\beta$ casein was used at a concentration of $20 \mu \mathrm{g} / \mathrm{ml}$; a concentration within the range our investigation deemed optimal (e.g. $10-50 \mu \mathrm{g} / \mathrm{ml}$ ). With respect to frequency of reactivity, our investigations suggest $\beta$ casein from Fluka was optimal for identifying such responses. The rationale underlying the differences observed in PBMC responses to the three manufactures' $\beta$ casein preparations is not known. Whereas the purity of the $\beta$ casein reported by all manufactures was high ( $\geq 80-90 \%$ ), we cannot exclude the possibility that some of the PBMC responses observed resulted from stimulation with non- $\beta$ casein cows' milk contaminants in the preparations, or that the variance resulted from small differences in the $\beta$ casein concentration in the manufacturers' products. Regardless of their source, more proliferative responses were observed in Type I diabetic patients and autoantibody negative relatives than in healthy control subjects.

In summary, in addition to indicating the need for appropriately matched subject groups when analysing cellular immune responses, these findings support our previous contention that individuals genetically prone to autoimmunity (compared with healthy control subjects) may be deficient in forming tolerance to dietary antigens [10]. Furthermore, the identification of anti- $\beta$ casein immunity in non-diabetic subjects means the hypothesis that this agent is implicated in the pathogenesis of Type I diabetes mellitus 
Table 1. Frequency and levels of cellular immune reactivities against $\beta$ casein in persons with or at varying risks for Type I diabetes. Manufacturer and concentrations used $(\mu \mathrm{g} / \mathrm{ml})$ for antigenic stimulation are indicated. Frequency values repre- sent percentages (number of positive individuals) for the indicated manufacturer and antigen concentration. Proliferation values are presented as stimulation indexes (means $\pm \mathrm{SD}$ ).

\begin{tabular}{|c|c|c|c|c|c|c|c|c|c|}
\hline \multirow{2}{*}{$\begin{array}{l}\text { Concentration } \\
(\mu \mathrm{g} / \mathrm{ml})\end{array}$} & \multicolumn{3}{|l|}{ Fluka } & \multicolumn{3}{|l|}{$\mathrm{ICN}$} & \multicolumn{3}{|l|}{ Sigma } \\
\hline & 1 & 10 & 50 & 1 & 10 & 50 & 1 & 10 & 50 \\
\hline \multicolumn{10}{|l|}{ Subject group } \\
\hline $\begin{array}{l}\text { Healthy contro } \\
\text { Frequency } \\
\text { Level }\end{array}$ & $\begin{array}{l}1(n=10) \\
0(0) \\
1.0(0.3)\end{array}$ & $\begin{array}{l}0(0) \\
1.2(0.5)\end{array}$ & $\begin{array}{l}0(0) \\
1.9(0.7)\end{array}$ & $\begin{array}{l}0(0) \\
1.0(0.2)\end{array}$ & $\begin{array}{l}10(1) \\
1.2(0.2)\end{array}$ & $\begin{array}{l}10(1) \\
1.5(0.7)\end{array}$ & $\begin{array}{l}0(0) \\
1.7(0.9)\end{array}$ & $\begin{array}{l}0(0) \\
1.9(0.8)\end{array}$ & $\begin{array}{l}0(0) \\
2.8(2.0)\end{array}$ \\
\hline $\begin{array}{l}\text { Autoantibody } \mathrm{n} \\
\text { Frequency } \\
\text { Level }\end{array}$ & $\begin{array}{l}\text { negative } r \\
21(6) \\
1.2(0.7)\end{array}$ & $\begin{array}{l}\operatorname{ves}(n=29 \\
48(14)^{\mathrm{c}} \\
3.2(2.9)^{\mathrm{a}}\end{array}$ & $\begin{array}{l}52(15)^{\mathrm{c}} \\
5.2(4.1)^{\mathrm{b}}\end{array}$ & $\begin{array}{l}17(5) \\
1.2(0.9)\end{array}$ & $\begin{array}{l}28(8) \\
1.7(1.6)\end{array}$ & $\begin{array}{l}24(7) \\
2.4(2.5)\end{array}$ & $\begin{array}{l}17(5) \\
2.4(1.0)\end{array}$ & $\begin{array}{l}34(10)^{\mathrm{a}} \\
3.4(2.4)\end{array}$ & $\begin{array}{l}24(7) \\
4.9(3.7)\end{array}$ \\
\hline $\begin{array}{l}\text { Newly-diagnos } \\
\text { Frequency } \\
\text { Level }\end{array}$ & $\begin{array}{l}\text { ed Type I } \\
9(3) \\
1.0(0.3)\end{array}$ & $\begin{array}{l}32) \\
31(10)^{\mathrm{a}} \\
2.4(2.1)\end{array}$ & $\begin{array}{l}62(20)^{\mathrm{d}} \\
5.0(3.7)^{\mathrm{b}}\end{array}$ & $\begin{array}{l}25(8) \\
1.2(0.6)\end{array}$ & $\begin{array}{l}44(14) \\
1.9(1.5)\end{array}$ & $\begin{array}{l}25(8) \\
2.3(1.7)\end{array}$ & $\begin{array}{l}25(8) \\
2.6(1.8)\end{array}$ & $\begin{array}{l}38(12)^{\mathrm{a}} \\
3.4(2.8)\end{array}$ & $\begin{array}{l}22(7) \\
4.7(3.7)\end{array}$ \\
\hline
\end{tabular}

Statistically significant difference from the control value at ${ }^{\mathrm{a}} p<0.05,{ }^{\mathrm{b}} p<0.03,{ }^{\mathrm{c}} p<0.01,{ }^{\mathrm{d}} p<0.005$

should be viewed with caution but not that it is negated. Further investigation is clearly needed to identify a role for diet on the natural history of this disease.

Acknowledgements. We thank Drs. William Winter, Janet Silverstein, and Michael Clare-Salzler for their assistance in obtaining patient materials. Supported in part by grants from the National Institutes of Health (DK45342, AI/DK39250, AI42288), Dairy Management Incorporated, The Juvenile Diabetes Foundation, and The American Diabetes Association.

\section{References}

1. Bach J-F (1994) Insulin-dependent diabetes as an autoimmune disease. Endocr Rev 14: 516-542

2. Maclaren NK, Atkinson MA (1992) Is insulin-dependent diabetes mellitus environmentally induced? N Engl J Med 327: 348-349

3. Dosch HM (1993) The possible link between insulin dependent (juvenile) diabetes mellitus and dietary cow milk. Clin Biochem 26: 307-308
4. Scott FW, Norris JM, Kolb H (1996) Milk and Type 1 diabetes: Examining the evidence and broadening the focus. Diabetes Care 19: 379-383

5. Ellis TM, Atkinson MA (1996) Early infant diets and insulin-dependent diabetes. Lancet 347: 1464-1465

6. Vaarala O, Klementti P, Savilahti E, Reijonen H, Ilonen J, Akerbloom HK (1996) Cellular immune response to cow's milk $\beta$-lactoglobulin in patients with newly-diagnosed IDDM. Diabetes 45: 178-182

7. Karjalainen J, Martin JM, Knip M et al. (1992) A bovine albumin peptide as a possible trigger of insulin-dependent diabetes mellitus. New Engl J Med 327: 302-307

8. Cavallo MG, Fava D, Monetini L, Barone F, Pozzilli P (1996) Cell-mediated immune response to $\beta$ casein in recent-onset insulin-dependent diabetes: implications for disease pathogenesis. Lancet 348: 926-928

9. Wasmuth HE, Becker F, Seebaum S, Elliott RB, Federlin K (1995) Association of antibodies to $\beta$ casein with type 1 diabetes. Autoimmunity 21: A328 (Abstract)

10. Atkinson MA, Bowman MA, Kao KJ, Dush PD, Simmel O, Maclaren NK (1993) Lack of immune responsiveness to bovine serum albumin in insulin-dependent diabetes. $\mathrm{N}$ Engl J Med 329: 1853-1858 